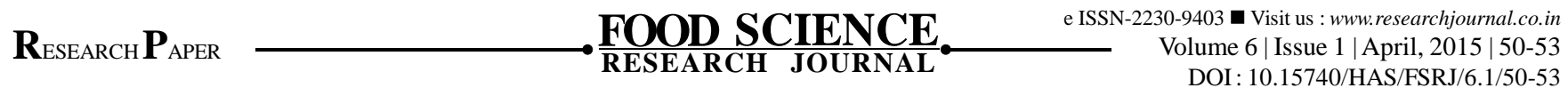

\title{
Diverse role of women life style, diet and health
}

\author{
Mamta Kumari and Vimi SinGH $_{\text {In }}$
}

Background and Objective : Diverse role of women lead towards negligence of their health and thus, scarcity of time and life style is driving towards unhealthy nutritional practices. Today processed food have an important position in the kitchen, therefore, in the present scenario these practices lead to obesity related diseases. The purpose of the study was to determine the prevalence of obesity and factor related to obesity risk in women of Bhagalpur due to unhealthy nutritional practices. Methodology: This community based study was conducted in the town of Bhagalpur (Bihar) in year 2010, 500 women aged 20 to 59 years old were included in the study. Data was collected using a questionnaire cum interview method. The questionnaire consisted of questions on socio - demographic (age, religion, education level, occupation, monthly income, marital status) gynaecological history, general dietary pattern and nutritional practices. In the present study BMI was used as main indicator of the degree of overweight and obesity among women. Results: The study finds that 40 per cent female was overweight whose BMI was 25.0 to $29.9 \mathrm{~kg} / \mathrm{m}^{2}$ and 25 per cent was obese whose BMI was 30.0 to $34.9 \mathrm{~kg} / \mathrm{m}^{2}$. Economic condition was positively co- related with the prevalence of over overweight and obesity. Work status of women does not show any clear relationship with overweight and obesity. Studies showed that higher BMI was clearly an important determinant of different disease, such 41 per cent suffering from diabetes, cardio-vascular, hypertension, thyroidism and arthritis. 21 per cent has heart disease and hypertension, 18 per cent heart disease, hypertension, thyroidism and arthritis, 12 per cent diabetes, heart disease and 8 per cent suffering from other diseases.

Key Words : Diverse role anthropometric, BMI, Life style, Physical exercise

How to cite this article : Kumari, Mamta and Singh, Vimi (2015). Diverse role of women life style, diet and health. Food Sci. Res. J., 6(1): $50-53$. 